\title{
Significado do processo de enfermagem para enfermeiros de uma unidade de terapia intensiva: uma abordagem interacionista*
}

\author{
THE MEANING OF THE NURSING PROCESS FOR NURSES OF INTENSIVE \\ THERAPY UNITS: AN INTERACTIONIST APPROACH \\ SIGNIFICADO DEL PROCESO DE ENFERMERÍA PARA ENFERMEROS DE UNA \\ UNIDAD DE CUIDADOS INTENSIVOS: UN ENFOQUE INTERACTIVO
}

\author{
Albertisa Rodrigues Alves ${ }^{1}$, Consuelo Helena Aires de Freitas Lopes ${ }^{2}$, Maria Salete Bessa Jorge ${ }^{3}$
}

\begin{abstract}
RESUMO
O estudo teve como objetivo compreender o significado da prática do Processo de Enfermagem para enfermeiros de uma unidade de terapia intensiva. Utilizamos o interacionismo simbólico e análise temática como referencial teórico-metodológico. Fizeram parte do estudo sete enfermeiros de unidade de terapia intensiva que vivenciam esta prática em um hospital público da cidade de Fortaleza, Ceará. A coleta de dados foi realizada no período de 01 de maio a 30 de agosto de 2006, por meio da observação participante e entrevista semiestruturada. Os resultados mostraram a interação social dos enfermeiros com os demais profissionais, os significados do processo de enfermagem e opiniões para a melhoria na UTI. A compreensão da experiência dos enfermeiros possibilitou reconhecer que as vivências são contraditórias e os significados são manifestados e expressos através da auto-interação e interação com outras pessoas.
\end{abstract}

\section{DESCRITORES}

Processos de enfermagem.

Unidades de Terapia Intensiva.

Relações interpessoais.

\begin{abstract}
The study aimed at comprehending the meaning of the Nursing Process practice for nurses in an intensive care unit. Symbolic interactionism and thematic analysis were used as the theoretical-methodological reference. Seven nurses from an intensive care unit who experience this practice in a public hospital in the city of Fortaleza, Ceará were part of the study. Data collection was performed from May $1^{\text {st }}$ to August $30^{\text {th }}$, 2006, using participative observation and semi-structured interviews. The results show the social interaction of the nurses with other professionals, the meanings of the nursing process and opinions for improving the ICU. The comprehension of the nurses' experiences allowed for the recognition that their experiences are contradictory and the meanings are manifested and expressed through self-interaction and interaction with other people.
\end{abstract}

\section{KEY WORDS}

Nursing process.

Intensive Care Units.

Interpersonal relations.

\section{RESUMEN}

El estudio tuvo como objetivo comprender el significado de la práctica del Proceso de Enfermería según enfermeros de una unidad de cuidados intensivos. Utilizamos la interacción simbólica y el análisis temático como referencial teórico metodológico. Fueron parte del estudio siete enfermeros de la unidad de cuidados intensivos, quienes son parte de esta práctica en un hospital público de la ciudad de Fortaleza, Ceará. La recolección fue realizada durante el 01 de mayo al 30 de agosto del 2006, a través de la observación participativa y la entrevista semiestructurada. Los resultados mostraron la interacción social de los enfermeros con los demás profesionales, los significados del proceso de enfermería y las opiniones para mejorar la atención en la $\mathrm{UCl}$. Comprender la experiencia de los enfermeros permitió reconocer que las vivencias son contradictorias y los significados son manifestados y expresados a través de la auto-interacción e interacción con otras personas.

\section{DESCRIPTORES}

Procesos de enfermería.

Unidades de Terapia Intensiva.

Relaciones interpersonales.

* Extraído da dissertação "O significado do processo de enfermagem para enfermeiros: uma abordagem interacionista", Universidade Estadual do Ceará, 2007. ${ }^{1}$ Enfermeira. Mestre em Enfermagem. Enfermeira da UTI do Hospital Geral de Fortaleza (HGF). Professora da Faculdade Católica Rainha do Sertão. Fortaleza, CE, Brasil. albertisarodrigues@terra.como.br ${ }^{2}$ Enfermeira. Professora Doutora da Universidade Estadual do Ceará (UECE). Coordenadora do Curso de Mestrado Acadêmico Cuidados Clínicos em Saúde e Área de Concentração em Enfermagem da Universidade Estadual do Ceará (UECE). Fortaleza, CE, Brasil. consueloaires@yahoo.com.br ${ }^{3}$ Enfermeira. Professora Doutora da Universidade Estadual do Ceará (UECE). Líder do Grupo de Pesquisa Saúde Mental, Família, Práticas de Saúde e Enfermagem Pesquisadora do CNPq. Fortaleza, CE, Brasil. masabejo@uece.br 


\section{INTRODUÇÃO}

Dentre as tecnologias da enfermagem, destaca-se o Processo de Enfermagem, que como metodologia de trabalho oferece diretrizes para o desenvolvimento da assistência de enfermagem com base no método científico, cujo propósito é identificar as necessidades humanas do cliente e implementar a adequada terapêutica de enfermagem ${ }^{(1-2)}$.

Observamos na prática, dificuldades na aplicação do Processo de Enfermagem e até mesmo a não aplicabilidade do mesmo, uma vez que as ações ficam centradas apenas no senso comum, não havendo planejamento, e, por conseguindamentação científica no desenvolvimento de ações que possam ser estudadas, discutidas e comprovadas na ciência da enfermagem. Isso é um dos aspectos que vem impossibilitando o crescimento da cientificidade da enfermagem. te, ficando difícil o raciocínio lógico em harmonia com a fun-

Sendo esta proposta teórica constituída por uma visão holística e integral do ser humano, o que temos percebido é que, na prática, nossas ações continuam fragmentadas, baseadas em sinais e sintomas da doença cuja resolução dos problemas permeia as respostas às demandas do serviço e nem sempre centradas na satisfação do paciente, ainda que biológicas. Observamos que o Processo de Enfermagem tornou-se mais uma tarefa burocrática a ser cumprida, assim, entendemos ser importante sua avaliação permanente na prática.

Desse modo, buscando compreender o que significa para os enfermeiros desenvolver o Processo de Enfermagem, como o mesmo age a partir dessa significação e como o enfermeiro se relaciona com as outras pessoas em relação a essa prática no cotidiano da terapia intensiva, é que desenvolvemos o estudo tomando como referência o Interacionismo Simbólico. Assim sendo, o presente estudo teve como objetivo compreender o significado da prática do Processo de Enfermagem para enfermeiros em unidade de terapia intensiva. é denominado de sistematização da assistência de enfermagem, metodologia da assistência de enfermagem ou processo de cuidar ${ }^{(3)} \mathrm{e}$ constitui-se de cinco etapas inter-relacionadas (investigação, diagnóstico, planejamento, implementação e avaliação) de forma sistemática e dinâmica para promover o cuidado humanizado, dirigido e orientado a resultados, acrescentando ainda seu baixo custo ${ }^{(4)}$.

No desenvolvimento das teorias de enfermagem, o foco do cuidado de enfermagem é a pessoa, em que algumas consideram o ser humano como um ser bio-psico-sócio-espiritual, muito além do modelo biomédico que centraliza sua ação na doença ${ }^{(5)}$. Entretanto, na prática clínica, observamos que as ações continuam fragmentadas, baseadas em sinais e sintomas da doença cuja resolução dos problemas permeia as respostas às demandas do serviço e nem sempre centradas na satisfação das necessidades da pessoa que está ali para receber o cuidado.

Portanto, entendemos que a aplicação do Processo de Enfermagem tem esbarrado em muitas dificuldades, prevalecendo na prática clínica um cuidado centralizado nas tarefas, resultando em um fazer automatizado e burocrático, cuja prioridade do serviço é o cumprimento de tarefas, em detrimento de um cuidado centrado nas necessidades do paciente. Além disso, o Processo de Enfermagem é uma estratégia e um instrumento de trabalho do enfermeiro, não significando um fim em si mesmo. Sem essa compreensão, o enfermeiro apenas cumprirá mais uma tarefa.

Há quase vinte anos temos desenvolvido o Processo de Enfermagem na prática assistencial em UTI de hospital público, a qual se fundamenta nas necessidades humanas básicas a partir da teoria da motivação humana de Maslow e na classificação de João Mohana contempladas na Teoria das Necessidades Humanas Básicas de Wanda de Aguiar Horta.

\section{FUNDAMENTAÇ̃̃O TEÓRICA}

A opção pelo emprego do referencial teórico do Interacionismo Simbólico, que tem sido utilizado com sucesso na Enfermagem, deu-se por se tratar de uma teoria em que o significado é o conceito central, onde as proposições teóricas ocorrem a partir da interação das pessoas dentro da estrutura social, as ações humanas definindo e participando do mundo(6).

Além disso, há a crença de que o Interacionismo Simbólico mostra respeito pela natureza da vida e da conduta do grupo humano, estando na vida grupal a condição essencial para a consciência, mundo de objetos e construção de atitudes ${ }^{(7)}$.

O Interacionismo Simbólico é uma perspectiva da Psicologia Social, sendo esta a única ciência social que retrata a ação do ser humano na relação com o mundo, focaliza a natureza da interação, a dinâmica social entre as pessoas e teve origem no fim do século XIX com destaque para George Herbert Mead, que como homem da ciência foi influenciado pelo pragmatismo filosófico e behaviorismo(6). Reúne estudos de figuras americanas notáveis, como George Herbert Mead, John Dewey, W. I. Thomas, Robert E. Park, William James, Charles Horton Cooley, Florian Znaniecki, James Mark Baldwin, Robert Redfield, e Louis Wirth ${ }^{(7)}$.

Mead foi professor da Escola de Chicago no período de 1893 a 1931. Fundamenta a teoria na descrição do comportamento humano, cujo dado principal é o ato social, concebido como comportamento externo observável e também como atividade encoberta no ato. Ele se opunha à teoria de John B. Watson, seguidor da Escola de lowa, que 
reduz o comportamento humano aos mecanismos ao nível infra-humano, cuja dimensão social é vista apenas como influente sobre o indivíduo ${ }^{(8)}$. Mead escreveu muitos artigos, mas a sua influência foi muito mais pelas publicações de leituras e notas por seus estudantes, bem como pela interpretação de seus trabalhos por vários sociólogos, especialmente por Herbert Blumer ${ }^{(7)}$. As suas obras foram compiladas e editadas após a sua morte em 1931, sendo a mais conhecida Mind, Self and Society que foi editada em $1934^{(9)}$.

Apesar de todos os escritos e apontamentos de Mead, que não teve a intenção de publicá-los em vida, coube a Blumer sistematizá-los e apresentar com clareza e fidelidade as idéias de Mead, sendo a sua obra principal publicada em 1969, Symbolic Interactionism, Perspective and Method, em que foram descritas as três premissas básicas do interacionismo simbólico ${ }^{(7)}$ :

\begin{abstract}
1. O ser humano age com relação às coisas na base dos sentidos que elas têm para ele. Estas coisas incluem todos os objetos físicos, outros seres humanos, categorias de seres humanos (amigos ou inimigos), instituições, idéias valorizadas (honestidade), atividades dos outros e outras situações que o indivíduo encontra na sua vida cotidiana.
\end{abstract}

2. O sentido destas coisas é derivado, ou surge, da interação social que alguém estabelece com seus companheiros.

3. Estes sentidos são manipulados e modificados através do processo interpretativo usado pela pessoa ao tratar as coisas que ela encontra.

Tópicos importantes do pensamento do autor, que junto com a visão de significado são essenciais para compreensão da teoria do Interacionismo Simbólico, definidos por: imagens radicais ou root images; vida em grupo; interação social; natureza dos objetos; pessoas como atores; natureza da ação humana, interligações das ações individuais na sociedade, mente, self, coisas, símbolos, linguagem, sociedade, auto-interação, ação humana e atividade grupal entre outros.

\section{MÉTODO}

Estudo qualitativo desenvolvido com eixo teórico no Interacionismo Simbólico, buscando a compreensão do significado da prática do Processo de Enfermagem para enfermeiros em unidade de terapia intensiva.

A abordagem da pesquisa qualitativa exige que o mundo seja examinado com a idéia de que nada é trivial, mas tudo tem potencial para construir uma pista que nos conduza a estabelecer uma compreensão mais clara do objeto em estudo ${ }^{(10-11)}$.

A pesquisa foi realizada com sete enfermeiros assistenciais de três unidades de terapia intensiva de um hospital geral de grande porte, da rede pública da cidade de Fortaleza, considerado referência no atendimento terciário na rede Sistema Único de Saúde (SUS) para o Estado do Ceará e Região Nordeste.
Como critérios de inclusão investigamos enfermeiros com tempo de graduação entre dois e vinte anos, tempo de serviço na instituição entre oito meses e 23 anos, e experiência com o Processo de Enfermagem, no mínimo de dois anos. Este último, pelo entendimento de ser tempo suficiente para o enfermeiro ter passado por todas as etapas de vivência do Processo de Enfermagem e ter condições de fazer uma avaliação crítica acerca do processo de trabalho da enfermagem.

O número de enfermeiros entrevistados seguiu o critério da saturação teórica, a qual baseia-se na repetição das idéias. A saturação é o critério de finalização, investigando-se diferentes representações apenas até que a inclusão de novos estratos não acrescente mais nada de novo ao estudo ${ }^{(12)}$.

O projeto de pesquisa foi encaminhado ao Comitê de Ética em Pesquisa da Universidade Estadual do Ceará e após parecer positivo, processo de $\mathrm{n}^{\circ} 06174148-5$, iniciamos a coleta dos dados seguindo as recomendações especificas em pesquisas com seres humanos.

Os dados foram coletados no período de 01 de maio a 30 de agosto de 2006 por meio da observação participante e entrevista semi-estruturada, nos turnos da manhã, tarde e noite.

Inicialmente para entrada de campo foram desenvolvidas observações participantes com o intuito de aproximação com a realidade a ser investigada. As pesquisas devem ser feitas através de um conhecimento participativo prévio dos fenômenos a serem investigados, sendo a observação participante um processo rigoroso de descoberta do mundo empírico em estudo, constituindo-se por duas fases: exploração e inspeção. A exploração é a fase preliminar onde o investigador faz uma sondagem minuciosa para determinação da natureza geral do fenômeno. A segunda fase, mais focalizada é a inspeção, diferenciando-se da exploração por ser mais aprofundada ${ }^{(7)}$.

A indagação estava centrada nos seguintes questionamentos: O que significa para os enfermeiros desenvolver o Processo de Enfermagem no seu dia-a-dia na UTI? Como o enfermeiro age a partir da interpretação da prática do Processo de Enfermagem no seu dia-a-dia na UTI? Qual o sentido do Processo de Enfermagem para o enfermeiro e como ele se relaciona com os outros em relação a essa prática no seu dia-a-dia na UTI?

Buscamos desenvolver a pesquisa seguindo os ensinamentos de que as pesquisas devem ser feitas através de um conhecimento participativo prévio dos fenômenos a serem investigados ${ }^{(7)}$

Portanto, os dados foram analisados à luz da perspectiva teórica do Interacionismo Simbólico, pautada nas premissas básicas e conceitos centrais da teoria. Para os procedimentos metodológico, optou-se pela análise categorial temática ${ }^{(13)}$.

Quanto às questões éticas e legais foram obedecidas as Diretrizes e Normas Reguladoras de Pesquisa envolvendo 
seres humanos, conforme a Resolução № 196 de 10 de outubro de 1996 do Conselho Nacional de Saúde ${ }^{(14)}$. Na preservação da identidade dos participantes, estes foram denominados de : $E_{1}, E_{2}, E_{3}, E_{4}, E_{5}, E_{6}$ e $E_{7}$.

\section{RESULTADOS}

Participaram do estudo enfermeiros com idade entre 26 e 58 anos, 3 (três) solteiros, 2 (dois) casados, 1(um) viúvo e 1 (um) divorciado.

Dos resultados da pesquisa, apresentaremos a temática A Interação Social de Enfermeiros na UTI: Significados e Crenças; e as categorias, Percebendo a equipe de enfermagem, Percebendo o Processo de Enfermagem mediante aos demais profissionais, A auto-interação, Repensando o Processo de Enfermagem que surgiram dos depoimentos dos enfermeiros quando manifestaram suas opiniões sobre a interação social com as demais pessoas na UTI acerca do Processo de Enfermagem, seja com os próprios colegas enfermeiros, auxiliares de enfermagem e demais profissionais. E auto-interagindo, os enfermeiros manifestaram a forma como se percebem desenvolvendo o Processo de Enfermagem, os significados que têm para eles, e repensando o Processo de Enfermagem os enfermeiros pontuaram formas de melhoria na UTI.

\section{Percebendo a equipe de enfermagem}

Esta categoria surgiu a partir da percepção que apresentaram em relação aos próprios colegas enfermeiros da UTI, das experiências compartilhadas em desenvolver o processo de enfermagem e desempenho dos auxiliares de enfermagem no envolvimento desta prática. Mediante aos depoimentos, observamos a espontaneidade em denunciar uns aos outros, sendo isto observado muito claramente nas falas de E3, E5 e E6 durante os momentos que falavam de como acontecia esta prática no dia-a-dia.

[...] tem muitos enfermeiros que fazem, mas também tem enfermeiros que não fazem [...] muitos colegas querendo que a coisa aconteça, embora também tenham muitos que emperram [...] existe ainda [...] uma relutância em usar o processo [...] $\left(\mathrm{E}_{3}, \mathrm{E}_{5}\right.$ e $\left.\mathrm{E}_{6}\right)$.

As falhas humanas no exercício da enfermagem podem ser consideradas éticas, expondo o paciente à situação de risco ou de danos, onde todas as ações estão diretamente e intrinsecamente ligadas à responsabilização do profissional, quando delas advém algum prejuízo ao paciente, em que múltiplos fatores podem contribuir para o desenvolvimento de ocorrência de riscos e de danos no processo de cuidar ${ }^{(15)}$.

Pudemos observar na fala de $E_{1}$, que a desvalorização dada ao Processo de Enfermagem pode ser evidenciada a partir da prática do enfermeiro no seu dia-a-dia, em que age de acordo com o significado que o mesmo tem para seu processo de trabalho. As ocorrências éticas são conflitos vivenciados por pessoas ou grupo de pessoas e que pautam suas ações nos valores pessoais e grupais valorizados socialmente ${ }^{(15)}$.

[...] não marca o diagnóstico de enfermagem relacionado a quê? [...] ela não marcou nada e ainda teve coragem de escrever o nome dela, assinatura $[\ldots]\left(E_{1}\right)$.

Outro aspecto de importante observação foi a divisão social do trabalho na enfermagem. Neste momento tivemos na mente as enfermeiras dominando o Processo de Enfermagem, fazendo igualmente o que os capitalistas fazem com os trabalhadores, ficando o auxiliar de enfermagem executando as tarefas e procedimentos necessários ao serviço, desconhecendo totalmente a ciência do processo de trabalho, uma vez que é responsabilidade do enfermeiro planejar o Processo de Enfermagem.

O processo ainda não está muito assim presente na nossa relação de auxiliar e enfermeiro [...] a gente não trabalha muito junto com o processo não [...] apesar deles saberem que existe a questão do Processo de Enfermagem, mas eles só fazem assim, numa realidade muito distante deles, eles não trabalham com isso [...] às vezes eu acho que o auxiliar não leu, às vezes eu acho que eles não dão muita atenção a isso [...] eles só têm a questão do trabalho mecânico $[\ldots]\left(E_{2}, E_{6}\right.$ e $\left.E_{7}\right)$.

Uma vez que o enfermeiro é o responsável pela concepção e gerenciamento do Processo de Enfermagem, deverá buscar estratégias de participação e envolvimento de todos, enfermeiros e auxiliares, para que a coisa possa fluir em uma rede de integração e interconexão das ações, não apenas cada um executando atividades independentemente um do outro.

Eu acho que ainda não está sendo respeitado de jeito nenhum [...] não adianta eu prescrever se não tiver uma sistematização onde toda a equipe entenda o que é aquilo ali o valor daquela prescrição, daquele cuidado $\left(E_{5}\right)$

A interpretação de E5 do não reconhecimento do Processo de Enfermagem por parte dos demais profissionais surge da construção social que tem com os demais profissionais na UTI. A explicação é de que cada pessoa constrói sua linha de ação à luz da atividade do outro, dirige o processo social das instituições, dos sistemas de classe, das divisões de trabalho e das organizações sociais de um modo geral. Ao contrário do que se pensa, não são as regras, normas e valores que dirigem o processo social do homem, mas o que eles fazem é que ditam e mantém a vida grupal $\left.\right|^{(7)}$.

Assim, a elaboração dos significados que o Processo de Enfermagem tem para os enfermeiros da UTI emergiu no processo de interação social, as pessoas são atores quando se engajam em ação, sendo capazes de abandonar, verificar, revisar e elaborar seu mundo de objetos.

\section{Percebendo o Processo de Enfermagem mediante aos demais profissionais}

A vida do grupo humano consiste e existe na combinação de linhas de ação com cada membro do grupo. Tal arti- 
culação de linhas de ação origina a ação conjunta( ${ }^{(8)}$. Dessa interação uns com outros, as pessoas formam objetos que constituem seu mundo e agem com base no significado que esses objetos têm para elas. Para compreender a ação conjunta é necessário adentrar o mundo de objetos, compreender como elas vêem e agem em relação àquele objeto. Requer colocar-se no lugar do outro, ver a situação conforme ela é vista pelo ator, observar o que o ator leva em consideração, observar como ele interpreta o que é levado em consideração por ele, observar os tipos de alternativas de atos que são mapeados pelo ator e procurar seguir a interpretação que o levou à linha de ação.

Os enfermeiros demonstram que a idéia de trabalho compartilhado e interativo entre as diversas categorias de profissionais não existe no dia-a-dia, pois cada profissional realiza sua atividade para a qual foi capacitado, inexistindo a complementaridade das ações.

A meu ver, os outros profissionais, não da equipe, ele ainda está imperceptível [...] não tem muito impacto [...] ele não é assim reconhecido sabe [...] é como se a evolução d'a gente fosse assim uma coisa insignificante $[\ldots]\left(E_{2}, E_{3}\right.$ e $\left.E_{5}\right)$.

O Processo de Enfermagem ainda é uma prática desconhecida por outros profissionais da saúde e isto permite a fragmentação das ações entre os mesmos e a redução do cuidado como procedimento, visto que, o que pode ter sido evidenciado como intervenção de enfermagem pelo enfermeiro, também existe como conduta por parte de outros profissionais que o enfermeiro tem total autonomia no desenvolvimento desse processo de trabalho.

No que tange ao modelo de formação dos profissionais de saúde tem sido pautado no modelo de assistência curativa da doença e na fragmentação do ser humano em partes isoladas, buscando a objetividade das ações, de modo que os saberes das diversas disciplinas raramente são compartilhados na busca da subjetividade tanto do cuidador como do ser que é cuidado. A preocupação entre os profissionais que atuam lado a lado no cotidiano evidencia o receio por parte de todos da perda de autonomia e espaço, tornando os locais de trabalho ambientes favoráveis à impessoalidade e de alta competitividade.

[...] eu nunca trato do processo com outros profissionais, só com os da equipe de enfermagem $\left(E_{5}\right)$.

A divisão do trabalho no hospital é a reprodução no seu interior da evolução e divisão de trabalho no modo de produção capitalista, preservando algumas características de religiosidade caritativo-assistencial do séc. XVIII, ao mesmo tempo que é acrescido de regras gerais de mercado típicas das sociedades capitalistas da atualidade ${ }^{(13)}$.

Dentro desse contexto de dissociação de papéis, de fragmentação das funções e dos saberes não terá sido surpresa a identificação empírica da realidade partida e repartida, delimitada por múltiplas disciplinas, onde cada um exerce sua função independentemente do todo.

\section{A auto-interação}

O enfermeiro, ao assumir o cuidado do paciente na UTI por meio do Processo de Enfermagem, traz consigo toda a experiência praticada no seu dia-a-dia, e mediante a sua vivência, passa a enfrentar as situações do cuidar, a interagir consigo mesmo e a assumir o cuidado, traçando suas linhas de ações, definindo as prioridades com base na avaliação do estado de saúde do paciente e tomando as diversas atitudes necessárias ao cuidado. Mediante esse processo de auto-interação, avalia o Processo de Enfermagem para a sua prática profissional, a sua importância, e os seus significados, construindo a partir disso, formas de pensar e agir.

Quando perguntamos aos enfermeiros qual o significado do Processo de Enfermagem em seu cotidiano, várias foram as expressões de significados através de sentimentos e opiniões que vieram à tona.

Bom, eu acho ele muito importante, profissionalmente porque faz com que a nossa profissão cresça [...] pode ser reconhecido [...] como um profissional valorizado [...] que vê o paciente como um todo $[\ldots]\left(E_{1}\right)$.

Significa uma qualidade de excelência de enfermagem ao meu paciente $\left(E_{2}\right)$.

Ao contrário de $\mathrm{E}_{3}$, que reforçou na prática a fragmentação das tarefas e a redução do ser humano em partes, pois se sente constrangido em não conseguir proporcionar o cuidado adequado, uma vez que a mesma reitera a visão funcionalista do trabalho da enfermagem.

Eu me sinto sem condições de executar o plano, de executar o plano e cuidar do doente [...] eu me sinto constrangida $[\ldots]\left(\mathrm{E}_{3}\right)$.

Envolvidos na mecânica dos afazeres rotineiros e pela cobrança de resultados positivos, os enfermeiros parecem não incorporar o Processo de Enfermagem como instrumento de trabalho que deve adequar-se às necessidades da clientela assistida e aos objetivos que vislumbrem o cuidado humano digno.

Para mim tem um significado muito importante se eu pudesse fazer como tal. Mas eu não posso fazer como tal, eu desprezo um pouco, porque eu não posso fazer como ele realmente precisa ser feito $\left(E_{3}\right)$.

Mesmo compartilhando problemas semelhantes, o significado que cada pessoa demonstra em relação ao mesmo objeto depreende das vivências individuais, interpretando e direcionando suas ações no complexo mundo social. Pudemos perceber que $\mathrm{E}_{4}$ direciona suas ações diárias a partir do Processo de Enfermagem, assumindo essa metodologia de trabalho como inerente à sua profissão. Através do planejamento e execução das intervenções de enfermagem, direciona suas atividades no cotidiano da UTI, objetivando o restabelecimento da saúde do paciente.

O processo significa p'ra mim a profissão, o que eu sou, o que eu faço dentro da UTI. Sem o processo, é como se o 
processo fosse o que eu tenho que seguir, o que eu tenho que fazer pelos meus pacientes $\left(E_{4}\right)$.

A expressão de sentimento de orgulho dita por $E_{5}$, construída no processo de interação social, faz parte da experiência desse enfermeiro que vivencia o cotidiano da UTI. A realização pessoal e profissional é ressaltada, pois particularmente direciona suas ações cuidativas baseadas no Processo de Enfermagem. Compreende que a validação e a comprovação de ações desenvolvidas dar-se-ão através desse instrumento de trabalho.

Muito importante pra mim, pra nós enfermeiros [...] valida o nosso trabalho, o nosso cuidar, aquilo que realmente comprova o que eu fiz, como eu faço, como eu planejo, como eu executo, para não ficar só nas idéias [...] p'ra mim é uma realização pessoal grande, profissional. Meu Deus, qual é o termo que eu diria? Eu poderia até usar o termo de um orgulho $[\ldots]\left(E_{5}\right)$.

Para os interacionistas simbólicos, o significado assume papel central no processo de interação social. O processo interpretativo dar-se através da auto-interação consigo e com os outros, leva a uma re-significação do vivido, em que os valores individuais e coletivos interferem no significado que as coisas têm para a pessoa ${ }^{(6,16-17)}$. Portanto, quando o enfermeiro tem que enfrentar e confrontar a situação na qual tem que atuar, ele ativamente constrói sua linha de ação, observando, mantendo e conferindo significados a partir da auto-interação individual e coletiva.

O Interacionismo Simbólico concebe a vida social, estabelecendo inter-relação conscienciosa pelo sentido atribuído às ações, sendo manipulado, redefinido e modificado através de processo interpretativo ${ }^{(7)}$.

\section{Repensando o Processo de Enfermagem}

Na presente investigação, evidenciamos conteúdos que manifestaram formas de repensar o Processo de Enfermagem numa perspectiva de melhor efetivação da prática com vistas a ocupar o espaço social mediante os demais profissionais da saúde e a própria instituição.

[...] será que, se tivesse informatização na sistematização eu não teria mais tempo com o meu paciente, para o cuidado? [...] vamos reformular nossa sistematização, pois vamos informatizar! $\left(E_{2}\right)$

Estudos $^{(1,18-19)}$ evidenciaram que a informatização do Processo de Enfermagem otimiza o tempo do enfermeiro para as ações cuidativas, essenciais para proporcionar um cuidado digno e humano, bem como para exercer atividades gerenciais que fazem parte do mundo do enfermeiro. Nesse aspecto, a vontade política e os objetivos da instituição deverão ser os mesmos, ou seja, a filosofia de trabalho dos diretores das instituições hospitalares bem como das diretoras de serviços de enfermagem têm que caminhar lado a lado. Podemos considerar uma utopia a ser perseguida? Que todos venham a responder, questionamento este que pertence a todos nós.
$\mathrm{Na}$ atual realidade, em que a saúde tornou-se uma mercadoria e os trabalhadores de enfermagem, produtores de serviços, com certeza a resposta será afirmativa. Entretanto, se repensarmos o nosso ensinar, vislumbrando a dimensão crítica dessa realidade e o nosso fazer, visando à mudança do status quo pela capacitação permanente dos trabalhadores, poderemos ter momentos de reflexão quanto a nossa prática assistencial, e não exclusivamente discussões acerca de problemas administrativos e burocráticos.

\section{CONSIDERAÇÕES FINAIS}

Em pesquisas de Enfermagem, observamos que a aplicação da teoria interacionista tanto no ensino e prática, buscam ampliar conhecimentos na construção de ações e estratégias voltadas para um relacionamento interativo e humanizado entre pessoas ${ }^{(20)}$. A experiência de fundamentar esta pesquisa com o Interacionismo Simbólico a partir da vivência cotidiana do enfermeiro de UTI que desenvolve o Processo de Enfermagem, mostrou que foi possível produzir conhecimentos nesta temática, no âmbito da prática e da pesquisa, baseados na compreensão do significado desta prática para o enfermeiro.

Refletindo o Processo de Enfermagem mediante a forma como cuida, como avalia o paciente e o significado deste para a sua prática, percebe-se cuidadora em conflito quanto à crença no Processo de Enfermagem, ora sente raiva, insatisfação, frustração, ora se orgulha, considerando este como forma de reconhecimento profissional e ocupação de espaço social da profissão com a conquista de autenticidade e liberdade de ação.

A partir da interação social com os demais, mediante o processo interpretativo, o enfermeiro passa a construir atitudes ao vivenciar o Processo de Enfermagem no cuidado do paciente da UTI. Sabemos que a maioria dos profissionais tem a formação no modelo tradicional de saúde, o pensamento e as ações centrados na doença e não na pessoa, de modo que o enfermeiro também faz parte desse contexto. Assim o enfermeiro considera o Processo de Enfermagem de forma positiva ou não, mostrando sentimentos, opiniões e valores no pensar e fazer a enfermagem.

Repensar novas estratégias que respondam às necessidades das pessoas que deverão também participar ativamente do processo saúde-doença, adaptando conceitos teóricos à realidade sócio-econômico-cultural em que atuamos, bem como o envolvimento ativo de todos os componentes da equipe de enfermagem, constitui a possibilidade de trilhar por outro caminho.

Embora percebendo que a atual realidade que vivemos ainda está muito longe da idealizada, pois nas nossas ações predominam a assistência demandada por procedimentos, normas, rotinas e focada na doença e não na pessoa doente. Compreendemos que utilizando uma metodologia de trabalho, neste caso o Processo de Enfermagem, e não simplesmente direcionando nossas ações pelo senso comum e pela prática empírica, vislumbraremos um novo futuro. 
Este estudo propiciou observar por meio de observações participantes que o enfermeiro, sobrecarregado de tarefas e afazeres cotidianos, relega para segundo plano o planejamento das atividades relacionadas ao Processo de Enfermagem e à equipe de enfermagem, sendo esporádicos encontros para discutir a assistência, o que pode favorecer ainda mais a desvalorização e a idéia de fazer burocrático.

\section{REFERÊNCIAS}

1. Crossetti MGO, Rodegheri M, D'Ávila ML, Dias VLM. O uso do computador como ferramenta para implementação do processo de enfermagem. Rev Bras Enferm. 2002;55(6):705-8.

2. Siviero IMPS, Toledo VP, Franco DAS. A motivação do aluno de graduação em enfermagem quanto à implantação do diagnóstico de enfermagem em sua futura prática profissional. Rev Enferm UERJ. 2002;10(2):90-3.

3. Carraro TE, Kletemberg DF, Gonçalves LM. O ensino da metodologia da assistência de enfermagem no Paraná. Rev Bras Enferm. 2003;56(5):499-501.

4. Alfaro-Lefevre R. Aplicação do processo de enfermagem: promoção do cuidado colaborativo. 5a ed. Porto Alegre: Artmed; 2005.

5. Souza MF. As teorias de enfermagem e sua influência nos processos cuidativos. In: Cianciarullo TI, Gualda DMR, Melleiro MM, Anabuki MH, organizadoras. Sistema de assistência de enfermagem: evolução e tendências. São Paulo: Ícone, 2001. p. 29-39.

6. Charon JM. Symbolic interacionism. 3 a ed. Englewood Cliffs: Prentice-Hall; 1989.

7. Blumer H. Symbolic interactionism: perspective and method. Englewood Cliffs: Prentice-Hall; 1969.

8. Haguette TMF. Metodologias qualitativas na sociologia. $3^{\mathrm{a}} \mathrm{ed}$. Petrópolis: Vozes; 1992.

9. Littlejohn SW. Fundamentos teóricos da comunicação humana. Rio de Janeiro: Guanabara Koogan; 1982.

10. Jorge MSB. Indo em busca de seu plano de vida: a trajetória do estudante universitário. Florianópolis: Papa Livro; 1997.

11. Turato ER. Métodos qualitativos e quantitativos na área da saúde: definições, diferenças e seus objetos de pesquisa. Rev Saúde Pública. 2005;39(3):507-14.
Acreditamos no Processo de Enfermagem como um meio e um instrumento que possibilita um fazer direcionado por ações científicas exeqüíveis na prática, não como um fim em si mesmo ou sinônimo de que sua mera aplicação promoverá a qualidade da assistência, se assim o for, permanecerá sendo uma forma de controle e um fazer desacreditado pela própria enfermagem.

12. Bauer MW, Gaskell G. Pesquisa qualitativa com texto, imagem e som: um manual prático. Petrópolis: Vozes; 2002.

13. Bardin L. Análise de conteúdo. Lisboa: Edições 70; 1977.

14. Conselho Nacional de Saúde. Resolução n. 196, de 10 de outubro de 1996. Dispõe sobre diretrizes e normas regulamentadoras de pesquisas envolvendo seres humanos. Bioética. 1996;4(2 Supl):15-25.

15. Freitas GF, Oguisso T, Merighi MAB. Motivações do agir de enfermeiros nas ocorrências éticas de enfermagem. Acta Paul Enferm. 2006;19(1):76-81.

16. Silva RM, Mamede MV. Conviver com a mastectomia. Fortaleza: EDUFC; 1998.

17. Lopes CHAF. Assumindo o cuidar: a enfermeira vivenciando o processo de cuidar e sendo cuidadora do paciente em nutrição parenteral [tese]. Fortaleza: Programa de Pós-Graduação em Enfermagem, Universidade Federal do Ceará; 2002.

18. Barros ALBL, Fakih FT, Michel JLM. O uso do computador como ferramenta para a implementação do processo de enfermagem: a experiência do Hospital São Paulo/UNIFESP. Rev Bras Enferm. 2002;55(6):714-9.

19. Évora YDM, Dalri MCB. O uso do computador como ferramenta para a implantação do processo de enfermagem. Rev Bras Enferm. 2002;55(6):709-13.

20. Lopes CHAF, Jorge MSB. Interacionismo simbólico e a possibilidade para o cuidar interativo em enfermagem. Rev Esc Enferm USP. 2005;39(1):103-8. 